\title{
Assessment of the Influence of 5-fluorouracil on the SMAD4 Gene Expression, Apoptosis induction and DNA Damage in the Human CACO-2 Cell Line
}

Agnieszka Wosiak ( $\sim$ agnieszka.wosiak@umed.lodz.pl )

Medical University of Lodz

Katarzyna Michalska

Medical University of Lodz

Jacek Pietrzak

Medical University of Lodz

Marek Mirowski

Medical University of Lodz

Ewa Balcerczak

Medical University of Lodz

Research Article

Keywords: Colorectal cancer, SMAD4, 5-fluorouracil, TGFß, cell line, CACO-2

Posted Date: May 26th, 2021

DOI: https://doi.org/10.21203/rs.3.rs-523538/v1

License: (c) (1) This work is licensed under a Creative Commons Attribution 4.0 International License.

Read Full License 


\section{Abstract}

Colorectal cancer (CRC) is the third most common cancer in the world. There are two major distinct precursor lesion pathways: the traditional adenoma-carcinoma pathway leading to most cases CRC, and the serrated neoplasia pathway. SMAD4 gene is involved in adenoma-carcinoma pathway.

The protein encoded by the SMAD4 gene is a key downstream signaling mediator in the TGF $\beta$ pathway. This pathway has tumor-suppressor functions, including cell-cycle arrest and apoptosis. Its activation in late-stage cancer can promote tumorigenesis, including metastasis and chemoresistance.

This study aimed to evaluate the effect of 5-fluorouracil (5-FU) on viability of advanced colorectal cancer cells and establishing whether the test compound may have an effect on the expression level of the SMAD4 gene, DNA damage and apoptosis. Chemotherapy based on 5-FU is used as an adjuvant treatment in most colorectal cancer patients.

The results obtained in the study showed that the use of 5-FU in low concentrations may not have a therapeutic effect, and may also influence drug resistance in cancer cells. Moreover, it has been shown that by using 5-FU at higher concentrations and prolonging the exposure time, SMAD4 gene expression is significantly increased which may have an impact on the effectiveness of the therapy.

\section{Introduction}

Colorectal cancer (CRC) is one of the most common malignancies and statistics show that it is the third cancer-related cause of death in the world. Despite the constantly developing knowledge on the etiopathogenesis of the neoplasm, a large percentage of patients diagnosed with colorectal cancer still die within five years following removal of the primary tumor due to cancer recurrence. Most cases of colorectal cancer are sporadic and are often diagnosed at an advanced stage of the disease.

Understanding the molecular basis of colorectal cancer development made it possible to use epigenetic and genetic changes as markers of cancer progression in clinical practice. It contributed to the achievement of significant progress in the treatment of patients ${ }^{1}$.

A common cytogenetic alteration observed in the development of colorectal cancer is the loss of genetic material in the region of the long arm of chromosome 18 where the SMAD4, SMAD2 genes and other tumor suppressor genes are located. The presence of the 18q21 chromosomal region deletion in patients with colorectal cancer is associated with a worse prognosis and poor survival. This is probably related to a loss of the important function that the SMAD4 gene fulfills in regulating growth, proliferation, differentiation and apoptosis of epithelial cells ${ }^{2}$. The protein encoded by the SMAD4 gene is a key downstream signaling mediator in the TGF $\beta$ pathway which plays complex functions in the control of critical biological processes in the gastrointestinal epithelium. Disturbances in the TGF $\beta$ signaling pathway component can lead to the development and progression of tumors, including colorectal cancer. The regulation of the cell cycle by the TGF $\beta$ tract can proceed in dual different ways, depending on the status of the SMAD and non-SMAD related pathways ${ }^{3}$. The pathway mediators protect the epithelial 
cells from excessive growth by directing them to the apoptosis and promote cell differentiation, however, the same elements stimulate neoplastic cell proliferation ${ }^{4}$. The SMAD4 gene, associated with the TGF $\beta$ trail is a tumor suppressor gene, and its loss disrupts TGF $\beta$ signaling. This gene plays a very important role in the progression of colorectal cancer since it is responsible for the regulation of transcription of many target genes, for example inflammation-related genes and pro-apoptotic genes. Moreover, SMAD4 is involved in the control of expression of growth factors such as VEGF ${ }^{5}$. SMAD4-deficient colonic epithelial cells have the ability to proliferate and metastasize ${ }^{1}$. The main cause of SMAD4 loss in the CRC is loss of heterozygosity ( $\mathrm{LOH})$. Nevertheless, there are also other mechanisms, as well as its lack of expression, that are related to a more aggressive course of the disease ${ }^{6,7}$. SMAD4 loss is also associated with a predisposition to chemoresistance to 5-fluorouracil (5-FU) used in the treatment of colorectal cancer. Probably the level of SMAD4 mRNA in patients with advanced colorectal cancer could be used as a genetic marker of the response to adjuvant therapy with 5 -FU. The mechanism by which SMAD4 regulates the chemosensitivity of patients with CRC undergoing adjuvant treatment has not been discovered so far 8-11.

Currently, the most effective therapeutic strategies for colorectal cancer include chemotherapy and radiation therapy following resection. Chemotherapy based on

5-fluorouracil is used as an adjuvant treatment in most colorectal cancer patients who are at high risk of relapse ${ }^{12,13}$. A common and unresolved problem faced when implementing an adjuvant therapy in patients with colorectal cancer is a phenomenon of multi-drug resistance to chemotherapeutic agents used. Fluorouracil represents the group of pyrimidine analogues which show a cytotoxic effect after conversion into biologically active cell cycle - specific metabolites. Three enzymes are involved in the metabolism of 5-FU in the body, i.e. dihydropyrimidine dehydrogenase, synthase thymidylate and methylenetetrahydrofolate reductase. The toxic effect of 5-FU on cancer cells is related to DNA damage through thymidylsynthetase inhibition. Consequently, this mechanism disrupts the synthesis of nucleic acids in a neoplastic cell, which contributes to the cell cycle arrest in the S phase, inhibition of cell division and ultimately cell apoptosis ${ }^{14}$.

In this study we evaluated the effect of 5-FU on viability of advanced colorectal cancer cells. We were also focused on establishing whether the test compound may have an effect on the expression level of the SMAD4 gene. The aim of this analysis was to find the grounds for the use of 5-FU in late-stage disease. It was confirmed that the expression level of the SMAD4 gene is a prognostic factor in patients with colorectal cancer, and it also plays an important role in the response to 5-FU treatment.

Understanding the mechanism that regulates SMAD4 gene expression can provide valuable information about the use of 5 -FU in the therapy selection process.

\section{Material And Methods}

\section{Material:}


The research evaluating the effect of 5-FU on the expression level of the SMAD4 gene and on apoptosis induction or DNA damage in colorectal cancer was conducted on a human colon cancer cell line (CACO2) commercially purchased by Sigma Aldrich, Germany. The company provides a certificate of authenticity for the CACO-2 cell line, with the number of ECACC 86010202. The manufacturer's data show, that the CACO-2 cells used for the research were originally derived from colon tissue obtained from a 72year-old Caucasian male diagnosed with colorectal adenocarcinoma. The selected CACO-2 cell line was characterized for different molecular markers. Based on the data collected in the analysis, cells derived from the CACO-2 cell line showed no structural changes within the SMAD4 gene.

\section{Cell culture:}

The CACO-2 cell line shows an adherent type of growth. The cells from the selected cell line were cultured in flasks with Eagle's Minimum Essential Medium supplemented with FBS and an antibiotic. The cells were grown in an incubator with a $5 \% \mathrm{CO}_{2}$ atmosphere, at the temperature of $37^{\circ} \mathrm{C}$ and the appropriate air humidity. When confluence of the cells was $70-80 \%$, the cell culture was passaged using trypsin.

\section{Assessment of cell viability by MTT assay}

The MTT test was performed to evaluate the 5-FU cytotoxicity effect on CACO-2 cells and to select an appropriate dose range of the studied drug. The assay was performed in a 96-well plate. Appropriately designed plates were seeded with a suspension of CACO- 2 cells at a density of $1.5 \times 10^{4}$ cells $/ \mathrm{ml}$ in a volume of $100 \mu \mathrm{l}$ per well. Then, after 24 hours the old medium was removed from the plate and the test compound dissolved in fresh culture medium was added to the wells in increasing concentrations. For this test, a 5 -FU solution was used at the following concentrations: $0.1,1,5,10,100,1000 \mu \mathrm{mol} / \mathrm{l}$. Both plates were incubated for 24 hours and 48 hours of exposure to 5-FU. Following the end of incubation, the medium containing the test compound was removed and the cells were treated with a solution of MTT with a final concentration of $5 \mathrm{mg} / \mathrm{ml}$. After a two-hour reaction at $37^{\circ} \mathrm{C}$, the formed formazan crystals were dissolved with a $20 \%$ solution of sodium lauryl dodecyl sulphate (SDS) in $1 \mathrm{M} \mathrm{HCl}$. The plates were placed in the incubator overnight. At the last stage, the plates were read colorimetrically by measuring the absorbance at a wavelength of $570 \mathrm{~nm}$. Based on these data, the effect of 5-FU on cell viability was assessed and the concentrations of the test compound were selected, which was further used in the next stages of the experiment to assess the level of SMAD4 gene expression after exposure to the 5-FU.

\section{Assessment of cell death by MUSE test kit}

The effect of 5-FU on the initiation of apoptosis in CACO-2 cells was assessed with a Guava Muse Cell Analyzer flow cytometer using the Muse ${ }^{\circledR}$ Annexin V \& Dead Cell Assay Kit. This method allows the detection of four cell populations, i.e. living cells, dead cells, and early and late apoptotic cells, based on binding of fluorescently labeled annexin V with phosphatidylserine (PS) located on the cell membrane. 
For the analysis, the cells of the CACO-2 line were cultured in 6-well plates. After a 24-hour incubation period, cells were treated with 5-FU solution in different concentrations, i.e. 0.1, 1, 5, 10, 100, and 1000 $\mu \mathrm{mol} / \mathrm{l}$ and the exposure was carried out for 24 hours. After this time, the cells were harvested from the surface of the wells in the plate using trypsin. The obtained cell suspensions in the culture medium were used for cytometer assay according to the manufacturer's instructions.

\section{Assessment of DNA damage by MUSE test kit}

An analysis of DNA damage through the ATM dependent pathway in the cell line CACO-2 under the influence of 5-FU was performed with a Guava Muse Cell Analyzer cytometer using a Flow Cellect MultiColor DNA Damage Response reagent kit. Based on the test it is possible to differentiate the analyzed cells into four groups, i.e. cells without DNA damage, ATM activated cells, H2A.X activated cells and cells with double DNA strand breaks using fluorescent-based analysis. For the assay, CACO-2 cells were grown in 6-well plates and treated with 5-FU at concentrations of $0.1,1,5,10,100$ and $1000 \mu \mathrm{mol} / \mathrm{I}$. After a 24hour exposure, cells were trypsinized from the plates into tubes and resuspended in culture medium, then centrifuged and washed with PBS (phosphate buffered saline) buffer solution. The obtained cell suspensions in PBS were used for the assay according to the manufacturer's instructions.

\section{Assessment of SMAD4 gene expression in 5-FU treated CACO-2 cells:}

\section{Exposure of CACO-2 cells to 5-FU:}

The 5-FU exposure procedure was performed in two 6-well plates. The first step was to apply a suspension of CACO-2 cells with a density of $1.5 \times 10^{4}$ cells $/ \mathrm{ml}$ on a plates in a volume of $3 \mathrm{ml}$ per well. The cell culture on the plates was carried out for 24hours. Subsequently, a series of dilutions of the test compound were prepared in antimicrobial-free culture medium. Having been seeded with cells, the prepared solutions of $5-\mathrm{FU}$ at concentrations of $0.1,1,5,10$ and $100 \mu \mathrm{mol} / \mathrm{I}$ were applied to the plate. CACO-2 cells incubated with growth medium only and not treated with the test compound were used as a negative control. After the set exposure time ( 24 hours and 48 hours), the old medium containing the test substance was removed from the plates and the procedure of collecting cells from the plate using trypsin was performed. In the last stage, the test cell suspensions were taken from the wells on the plate into test tubes, centrifuged, washed twice with the buffer solution and finally suspended in PBS. The prepared cells treated with $5-\mathrm{FU}$ were stored at $-80^{\circ} \mathrm{C}$ until RNA isolation was performed.

\section{RNA isolation from 5-FU-treated cells:}


In order to evaluate the effect of 5-FU on the expression level of the SMAD4 gene in the CACO-2 cell line, isolation of RNA was performed using the column method with Genomic Midi Kit (A\&A Biotechnology, Poland) in accordance with the manufacturer's protocols. The concentration and purity of RNA obtained

after isolation was assessed spectrophotometrically. RNA samples that had the ratio of the absorbance at $260 / 280 \mathrm{~nm}$ between of $1.8-2.0$ were selected for further study.

\section{Reverse transcription reaction}

Total RNA obtained from the 5-FU treated cell line was subjected to a reverse transcription reaction to complementary DNA (cDNA) using High - Capacity cDNA Reverse Transcription Kit (Applied Biosystems ${ }^{T M}$, USA) according to the manufacturer's protocol. The final RNA concentration of $0.005 \mu \mathrm{g} / \mu \mathrm{l}$ was determined for each sample. The presence of cDNA in the samples was checked by PCR for the $G A P D H$ reference gene. Samples which confirmed the presence of $189 \mathrm{bp} \mathrm{PCR}$ product were stored at $-20^{\circ} \mathrm{C}$ for further analysis.

\section{Real - time PCR}

Quantitative analysis of the expression level of SMAD4 mRNA as compared to the GAPDH reference gene was carried out using the Real-time PCR technique on a Bio-Rad apparatus (CFX Connect Real-Time PCR Detection System) in accordance with the manufacturer's protocol. The real-time reaction was performed with a non-specific fluorescent dye, using the iTaq Universal SYBR Green Supermix reagent kit (BioRad, USA). The composition of the reaction mixture for both genes included $5 \mu$ of mix reagent, $0.25 \mu \mathrm{l}$ of 10 $\mu \mathrm{mol} / \mathrm{l}$ each primer solution, $1 \mu \mathrm{l}$ of cDNA template and nuclease-free water to a final reaction volume of $10 \mu \mathrm{l}$. The sequences of the primers used for the reactions were GAPDHF 5'-

TGGTATCGTGGAAGGACTCATGAC-3'; GAPDHR 5'-ATGCCAGTGAGCTTCCCGTTCAGC-3'; SMAD4 F 5'GCCTGATCTTCACAAAAATG-3'; SMAD4 R 5'-GATCAATTCCAGGTGATACAAC-3'. Real-time PCR reactions for SMAD4 and GAPDH were run simultaneously, in separate tubes and in triplicate for each sample. A triplicate negative control amplification reaction was performed for each experiment. The thermal cycling conditions for the reaction were initial denaturation step at $95^{\circ} \mathrm{C}$ for three minutes, 39 cycles with two steps, i.e. denaturation at $95^{\circ} \mathrm{C}$ for $10 \mathrm{sec}$, annealing with elongation at $58^{\circ} \mathrm{C}$ for $30 \mathrm{sec}$. To confirm Realtime reaction specificity, the melting curve analysis for each amplification product was performed. The mean of the obtained $\mathrm{Ct}$ values for GAPDH and SMAD4 genes was calculated. To assess the relative level of SMAD4 expression the $\triangle \triangle \mathrm{Ct}$ method was used.

\section{Results}

\section{The results of the MTT assay}

The viability of the 5-FU-treated cells was assessed using the MTT test. The percentage viability was calculated as (drug-treated cells absorbance/ control cells absorbance) x 100\%. MTT cell proliferation 
assay was applied to check the IC50 value for 5-FU in the CACO-2 cells. The results obtained in the test are presented in Fig. 1. Based on experimental results, it was estimated that the CACO-2 cell line showed resistance to 5-FU applied in the concentration of 0.1-10 $\mu \mathrm{mol} / \mathrm{l}$, both during the 24-hour and 48-hour exposure. The effect of 5-FU on the viability of colorectal cancer cells was only observed at the highest concentrations of 5-FU, i.e. $100 \mu \mathrm{mol} / \mathrm{l}$ and $1000 \mu \mathrm{mol} / \mathrm{l}$. Using these drug concentrations, the viability of CACO- 2 cells decreased to the values of $66.59 \%$ and $64.38 \%$ (for $100 \mu \mathrm{mol} / \mathrm{l}$ at 24 -hour and 48 -hour exposure time) and to the values of $60.3 \%$ and $58.37 \%$ (for $1000 \mu \mathrm{mol} / \mathrm{l}$ at 24 -hour and 48 -hour exposure time). 5-FU chemoresistance is a common phenomenon in colorectal cancer patients, especially in advanced stages of the disease. Use of high doses of the drug in these patients carries a risk of lifethreatening adverse effects related to study drug toxicity. It should be established in clinical trials whether the used 5-FU in concentrations influencing cell viability does not cause acute toxicity.

\section{The results of the flow cytometry assays}

The results of the flow cytometry tests are shown in Figs. 2 and 3. Based on the presented findings, it was confirmed that 5-FU used in concentrations of $0.1-10 \mu \mathrm{mol} / \mathrm{I}$ does not significantly affect cell apoptosis or cause DNA damage. In the case of applying 5-FU at a concentration above $100 \mu \mathrm{mol} / \mathrm{I}$ a greater percentage of CACO-2 dead cells or in the late stage of apoptosis was observed. At a concentration of $100 \mu \mathrm{mol} / \mathrm{l}$, the percentage of dead cells was 12.45 , while at a concentration of $1000 \mu \mathrm{mol} / \mathrm{l}$, it was 14.54. Similar conclusions were drawn based on another assay. Cells treated with 5-FU in concentrations above $100 \mu \mathrm{mol} / /$ showed more frequent changes related to DNA damage as compared to control cells. For 5-FU used at the concentration of $100 \mu \mathrm{mol} / \mathrm{l}$, an increase in the number of cells with total DNA damage to the value of $20.58 \%$ was observed as compared to the control, where the value was $5.71 \%$. For the concentration of $1000 \mu \mathrm{mol} / \mathrm{l}$, the number of these cells increased to $29.5 \%$ according to the used control. The percentage of single positive phosphorylated form of H2A.X (pH2A.X) cells within cells treated with 5-FU at a concentration of 100 and $1000 \mu \mathrm{mol} / \mathrm{I}$ was 9.23 and 19.4 , respectively, while in the control it was 2.6. The incidence of cells with double strand breaks also increased to about $10 \%$ for the two highest concentrations of 5-FU. The observed in vitro changes in CACO-2 cells caused by 5-FU may be of clinical relevance for the choice of drug concentration in the treatment of patients with colorectal cancer. Perhaps high concentrations of the analyzed drug overcome the resistance of cells to 5-FU.

\section{The results of the evaluation of the relative expression level of the SMAD4 gene in CACO-2 cells treated with 5-FU}

In the quantitative analysis performed, the assumed level of reaction efficiency was $100 \%$. The double delta method was used to calculate the relative expression ratio (R) of the SMAD4 gene. The obtained results are presented in Fig. 4. The resulting observations indicate a tendency related to the decrease of the SMAD4 gene expression level in CACO-2 cells under the influence of 5-FU at lower concentrations $(0.1-10 \mu \mathrm{mol} / \mathrm{I})$. The inverse dependency was found in the case of using 5-FU at a concentration of 100 
$\mu \mathrm{mol} / \mathrm{l}$. At this concentration, 5-FU appears to produce the effect of increasing the relative expression level of the SMAD4 gene, especially when the cells are exposed to the drug for a longer time. High expression of the SMAD4 gene is a desirable predictor in patients with colorectal cancer, especially in advanced stages. Hence, the assessment of the expression of the studied gene before the initiation of treatment is a reasonable procedure that can be used to estimate the benefits of the applied therapy. Additionally, the effect of the specific concentration of 5-FU used on the regulation of the SMAD4 gene expression may also be important for the effectiveness of the therapy.

\section{Discussion}

5-FU is widely used in the treatment of patients with colorectal cancer. One of the main problems limiting the application of a thymidylate synthase inhibitor in oncological therapy is the common occurring chemoresistance manifested by the lack of response of tumor cells to a chemotherapeutic agent used. In colorectal cancer, the expression level of the SMAD4 gene is involved in inducing resistance to 5-FU-based therapy. The molecular mechanism leading to the development of this phenomenon is unknown. Many scientific reports show that patients with reduced level of SMAD4 gene expression are at higher risk of 5FU induced resistance. In a report on the role of the SMAD4 gene as a predictive marker in the therapy based on 5-FU, Boulay et al. prove that patients with colorectal cancer and normal expression of the SMAD4 gene gain significantly greater benefits from the introduced adjuvant therapy. The authors documented their observations with a conclusion on the action of 5-FU in a SMAD4-dependent manner 15. Moreover, the SMAD4 gene plays a very important role in the development of colorectal cancer, and especially the loss of this gene contributes to the progression to metastatic form of this cancer. The report by Pia Alhopuro et al. confirmed a significant connection between the low tumor level of the SMAD4 protein and decreased SMAD4 mRNA expression, which results in poor prognosis in a patient with a high risk of disease recurrence after treatment ${ }^{16,17}$. Reduced SMAD4 expression is associated with the activation of the PI3K / Akt pathway and increased VEGF expression in colon cancer cells, which promotes cancer progression and the escape of cells from apoptosis. Moreover, the disruption of the apoptotic pathway may be caused by overexpression of $\mathrm{BCl}-2$ and $\mathrm{BCl}-\mathrm{w}$ genes responsible for inhibition of cell death, depending on the level of SMAD4 expression ${ }^{18,19}$. The role of 5 -FU is based on directing neoplastic cells into the apoptotic pathway through the inhibition of thymidylsynthetase. The correlation between 5-FU resistance and the expression level of SMAD4 gene may suggest a significant contribution of this gene to the 5-FU dependent apoptosis ${ }^{20,21}$.

In this study, an analysis was performed to evaluate changes in the expression level of the SMAD4 gene under the influence of 5-FU applied at various concentrations. A cell line derived from advanced colorectal cancer was used for the study. The results obtained in the test showed resistance of CACO-2 cells to 5-FU. This may be due to possibly decreased expression of the SMAD4 gene in cells. Additionally, it was found that the relative expression level of the SMAD4 gene was significantly reduced in the CACO-2 line cells treated with $5-\mathrm{FU}$ at concentrations of $0.1-10 \mu \mathrm{mol} / \mathrm{l}$ as compared to cells not treated with the drug. This 
observation may indicate the possibility of generating drug resistance of colorectal cancer cells associated with the use of 5-FU in low concentrations, which proves that this drug does not exert any influence on the viability of CACO-2 cells. The use of 5-FU at low concentrations may not bring a therapeutic effect, however, it may also have a negative result on tumor cells that become resistant. Moreover, it has been shown that if 5 -FU is applied at a concentration above $100 \mu \mathrm{mol} / \mathrm{l}$ and the time of cell exposure to the test compound is extended, the expression of the SMAD4 gene increases significantly. This observation may indicate the effect of the tested chemotherapeutic agent on the expression level of the SMAD4 gene, which may contribute to overcoming drug resistance in colorectal cancer cells. Based on the preliminary results presented in the paper, a more thorough analysis should be carried out, including other colorectal cancer cell lines, and the research should also involve in vivo evaluation. In this report, 5-FU was used at various concentrations, however, only the highest ones showed an effect on the expression level of the SMAD4 gene. The possibility of obtaining an appropriate concentration of 5-FU in colorectal cancer cells in in vivo studies may help to overcome resistance to the chemotherapeutic agent used, increase the effectiveness of the treatment and thus significantly improve the patient's prognosis.

\section{Declarations}

\section{Funding:}

Research supported by statutory funds of the Department of Pharmaceutical Biochemistry and Molecular Diagnostics, Medical University of Lodz, 503/3-015-02/503-31-001.

\section{Competing interests:}

The authors declare no competing financial interests or personal relationships that could have an impact on the work presented in the paper.

\section{Data availability:}

The data sets generated during the current study are available from the corresponding author on reasonable request. Requests for data should be addressed to AW.

\section{Code availability:}

Not applicable.

\section{Authors' contributions:}


All authors contributed to the development of the study design. EB and AW participated in overseeing the research project. AW developed a research plan and participated in its implementation. JP and AW conducted data analysis. AW, MM and KM wrote the manuscript. All authors read and approved the final manuscript.

\section{Ethics declarations:}

Not applicable

\section{Consent to participate:}

Not applicable

\section{Consent to publish:}

Not applicable

\section{References}

1. Isaksson-Mettävainio, M., Palmqvist, R., Forssell, J., Stenling, R. \& Oberg, A. SMAD4/DPC4 expression and prognosis in human colorectal cancer. Anticancer Res 26, 507-510 (2006).

2. Derynck, R. \& Zhang, Y. E. Smad-dependent and Smad-independent pathways in TGF- $\beta$ family signalling. Nature. 425, 577-584 https://doi.org/10.1038/nature02006 (2003).

3. Kurokowa, M., Lynch, K. \& Podolsky, D. K. Effects of growth factors on an intestinal epithelial cell line: Transforming growth factor $\beta$ inhibits proliferation and stimulates differentiation. Biochemical and Biophysical Research Communications. 142, 775-782 https://doi.org/10.1016/0006291x(87)91481-1 (1987).

4. Itatani, Y., Kawada, K. \& Sakai, Y. Transforming Growth Factor- $\beta$ Signaling Pathway in Colorectal Cancer and Its Tumor Microenvironment. International Journal of Molecular Sciences. 20, 5822 https://doi.org/10.3390/ijms20235822 (2019).

5. Maitra, A., Molberg, K., Albores-Saavedra, J. \& Lindberg, G. Loss of Dpc4 Expression in Colonic Adenocarcinomas Correlates with the Presence of Metastatic Disease. The American Journal of Pathology. 157, 1105-1111 https://doi.org/10.1016/s0002-9440(10)64625-1 (2000).

6. Miyaki, M. et al. Higher frequency of Smad4 gene mutation in human colorectal cancer with distant metastasis. Oncogene. 18, 3098-3103 https://doi.org/10.1038/sj.onc.1202642 (1999).

7. Kozak, M. M. et al. Smad4 inactivation predicts for worse prognosis and response to fluorouracilbased treatment in colorectal cancer. Journal of Clinical Pathology. 68, 341-345 https://doi.org/10.1136/jclinpath-2014-202660 (2015). 
8. Wasserman, I. et al. SMAD4 Loss in Colorectal Cancer Patients Correlates with Recurrence, Loss of Immune Infiltrate, and Chemoresistance. Clin Cancer Res. 25, 1948-1956 https://doi.org/10.1158/1078-0432.Ccr-18-1726 (2019).

9. Watanabe, T. et al. Molecular Predictors of Survival after Adjuvant Chemotherapy for Colon Cancer. New England Journal of Medicine. 344, 1196-1206 https://doi.org/10.1056/nejm200104193441603 (2001).

10. Ahn, B. K., Jang, S. H., Paik, S. S. \& Lee, K. H. Smad4 May Help to Identify a Subset of Colorectal Cancer Patients with Early Recurrence after Curative Therapy. Hepatogastroenterology. 58, https://doi.org/10.5754/hge11186 (2011).

11. de Gramont, A. et al. Leucovorin and Fluorouracil With or Without Oxaliplatin as First-Line Treatment in Advanced Colorectal Cancer. Journal of Clinical Oncology. 18, 2938-2947 https://doi.org/10.1200/jco.2000.18.16.2938 (2000).

12. Fanciullino, R. et al. In vitro and in vivo reversal of resistance to 5-fluorouracil in colorectal cancer cells with a novel stealth double-liposomal formulation. British Journal of Cancer. 97, 919-926 https://doi.org/10.1038/sj.bjc.6603970 (2007).

13. Lee, Y. J. et al. 5-Fluorouracil as a Tumor-Treating Field-Sensitizer in Colon Cancer Therapy. Cancers 11, 1999, doi:10.3390/cancers11121999 (2019).

14. Boulay, J. L. et al. SMAD4 is a predictive marker for 5-fluorouracil-based chemotherapy in patients with colorectal cancer. British Journal of Cancer. 87, 630-634 https://doi.org/10.1038/sj.bjc.6600511 (2002).

15. Alhopuro, P. et al. SMAD4 Levels and Response to 5-Fluorouracil in Colorectal Cancer. Clin. Cancer Res. 11, 6311-6316 https://doi.org/10.1158/1078-0432.ccr-05-0244 (2005).

16. Alazzouzi, H. et al. SMAD4 as a Prognostic Marker in Colorectal Cancer. Clin. Cancer Res. 11, 26062611 https://doi.org/10.1158/1078-0432.ccr-04-1458 (2005).

17. Touil, Y. et al. Colon Cancer Cells Escape 5FU Chemotherapy-Induced Cell Death by Entering Stemness and Quiescence Associated with the c-Yes/YAP Axis. Clin. Cancer Res. 20, 837-846 https://doi.org/10.1158/1078-0432.ccr-13-1854 (2013).

18. Wang, W., Marsh, S., Cassidy, J. \& McLeod, H. L. Pharmacogenomic dissection of resistance to thymidylate synthase inhibitors. Cancer Res. 61, 5505-5510 (2001).

19. Zhang, B. et al. Smad4 sensitizes colorectal cancer to 5-fluorouracil through cell cycle arrest by inhibiting the PI3K/Akt/CDC2/survivin cascade. Oncol. Rep. 35, 1807-1815 https://doi.org/10.3892/or.2015.4479 (2015).

20. Zhang, B. et al. Loss of Smad4 in colorectal cancer induces resistance to 5-fluorouracil through activating Akt pathway. British Journal of Cancer. 110, 946-957 https://doi.org/10.1038/bjc.2013.789 (2014).

21. 21. Zhang, B. et al. Loss of Smad4 in colorectal cancer induces resistance to 5-fluorouracil through activating Akt pathway. British Journal of Cancer 110, 946-957, doi:10.1038/bjc.2013.789 (2014). 
Figures

\section{CACO-2 cell viability after 5-FU exposure}

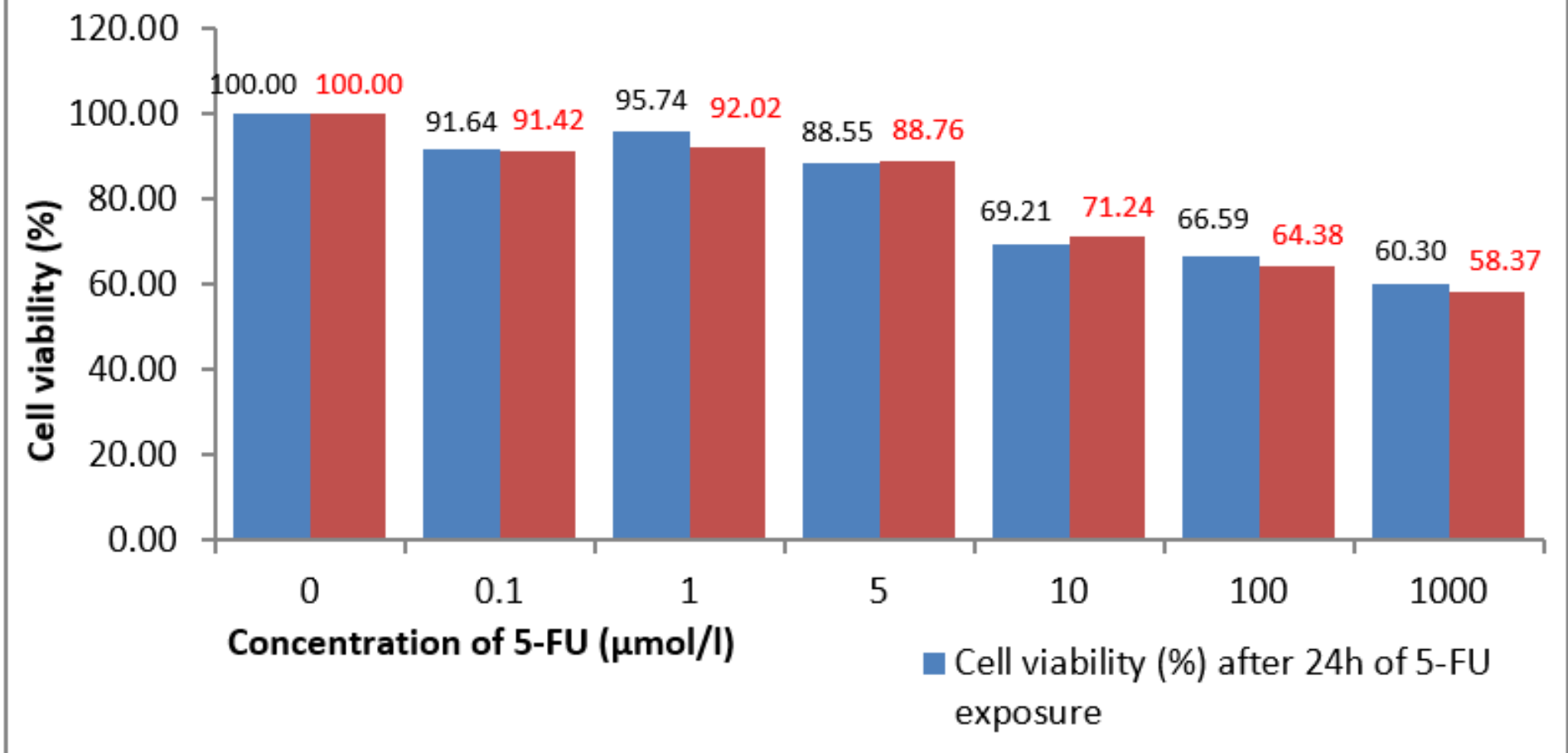

Figure 1

MTT results of viability of CACO-2 cells treated with 5-FU 


\section{Effect of 5-FU on the induction of apoptosis}

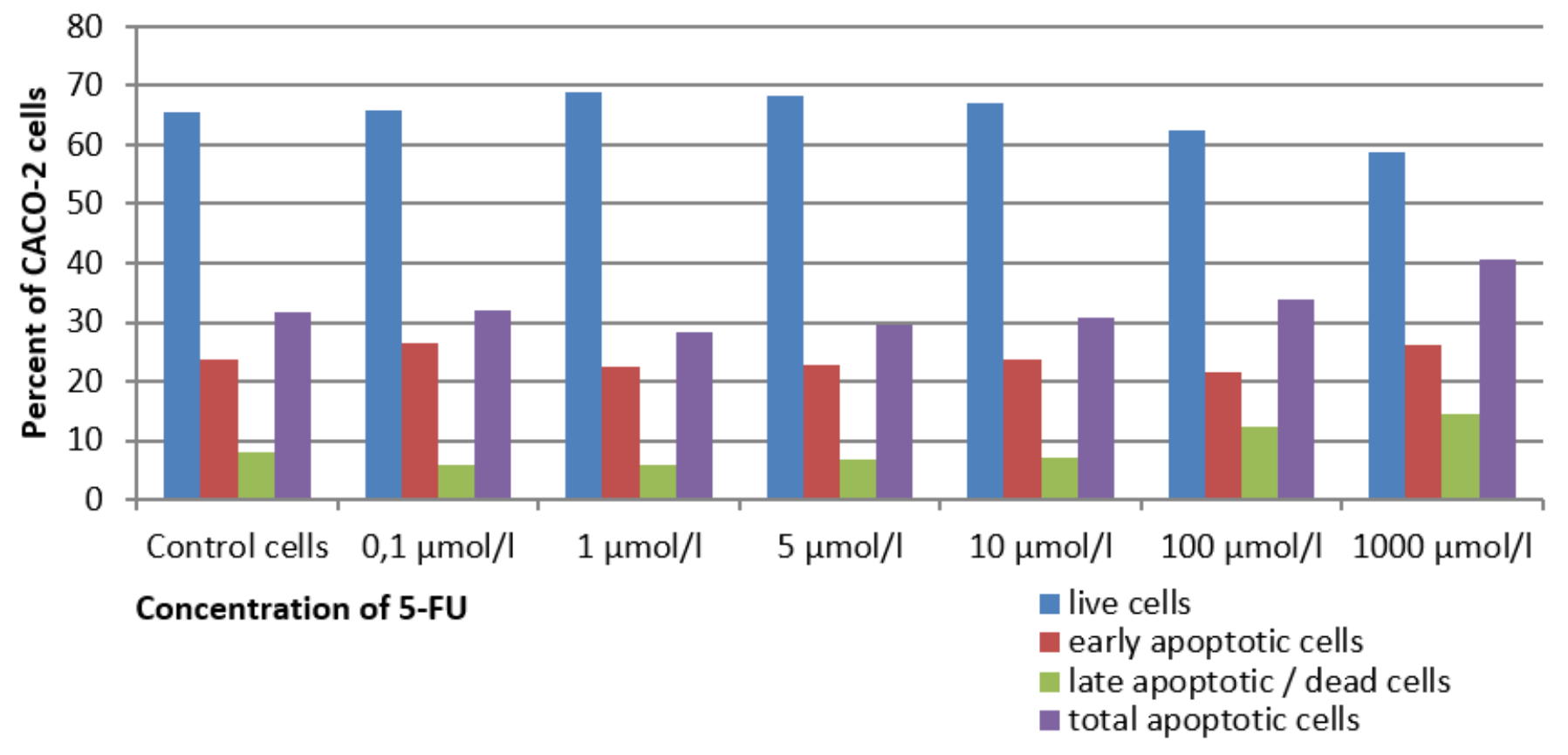

Figure 2

The effect of 5-FU on the induction of apoptosis

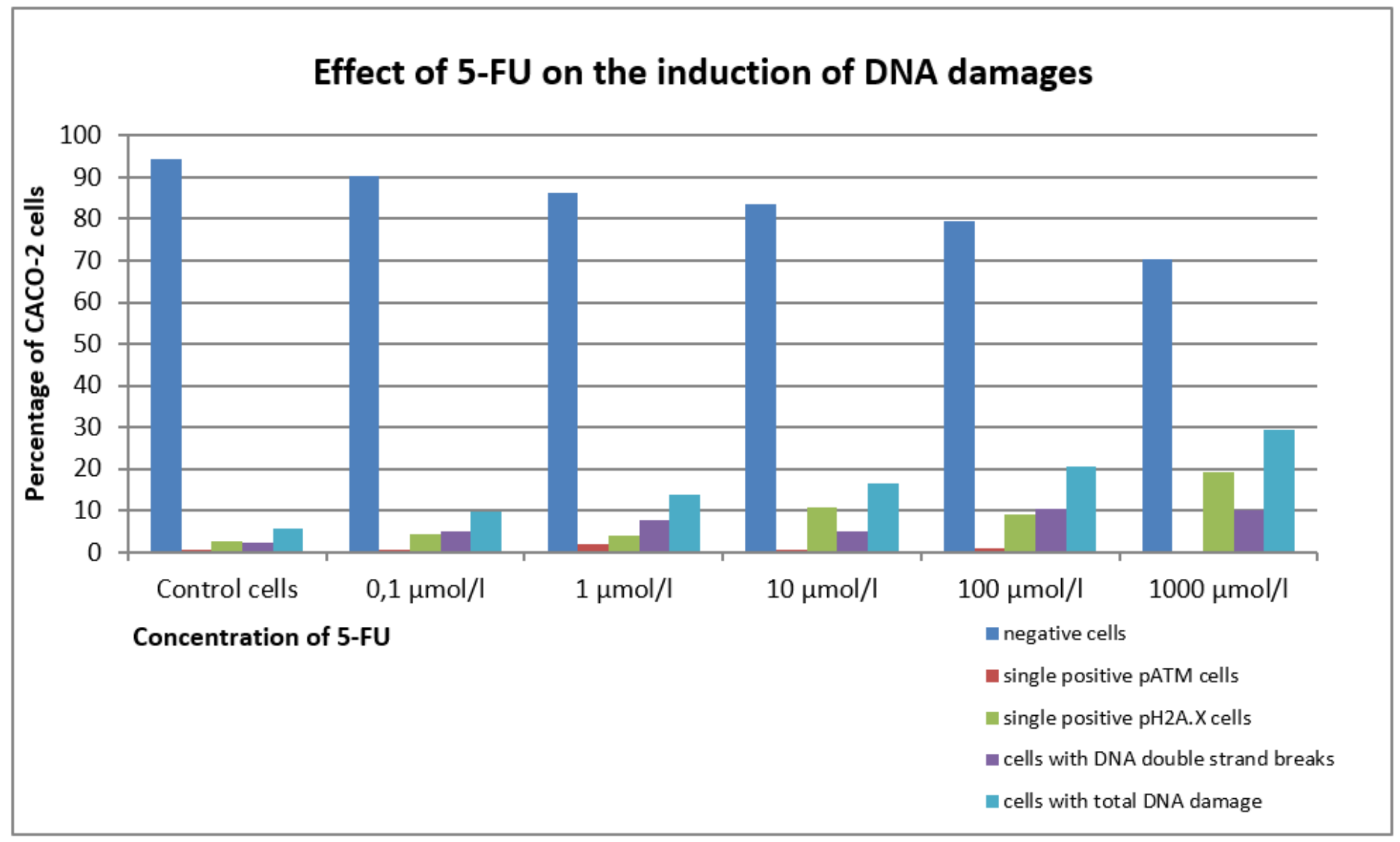


Figure 3

The effect of 5-FU on the induction of DNA damage

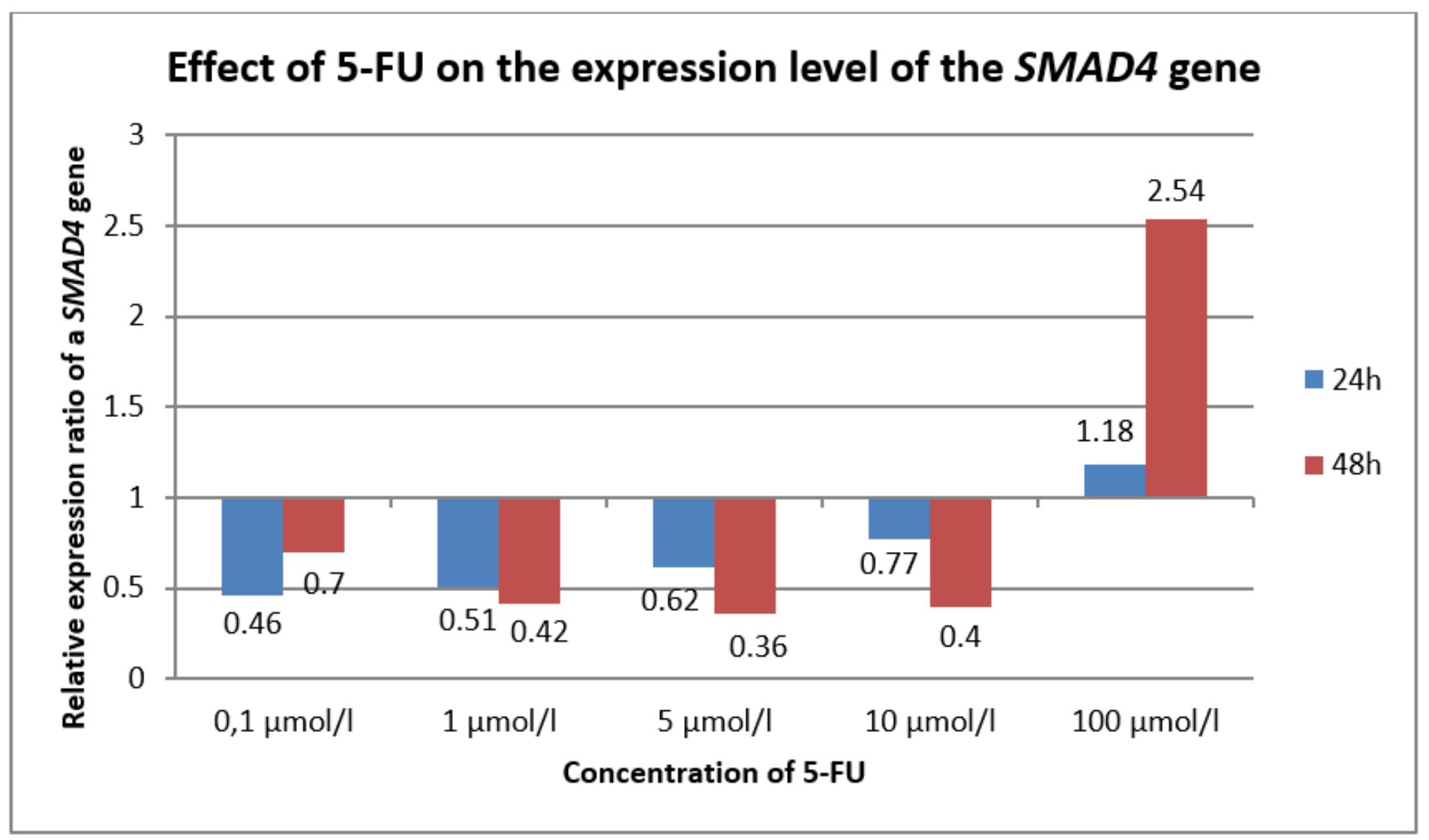

Figure 4

The effect of 5-FU on the expression level of the SMAD4 gene 